\title{
The Female Body and Experience in Chinese Multiplayer Online Battle Arena Games
}

\author{
Suoyi Zhang ${ }^{1, *}$ \\ ${ }^{1}$ Department of English, Faculty of Arts and Humanities, King's College London, Strand, London, WC2R2L5, United \\ Kingdom. \\ *Corresponding author. Email: k1924746@kcl.ac.uk
}

\begin{abstract}
This paper sets out to discuss the implications of female representation in Chinese Multiplayer Online Battle Arena (MOBA) games for female players. Due to the sexist treatment of women in the gaming sphere, this paper hopes to open new discussions of how visual representation of women in games is harmful for female players. By examining a 2020 case study conducted by Tingting Liu and Zishan Lai on a top Chinese MOBA and applying various works by Judith Butler, Mary Ann Doane and Laikwan Pang, gaming is considered as a performance, masquerade or distorting mirror in which gender is explored. The visual representation of women in games puts forward a distorted view of female players and therefore influences the way male players view female players and how female players view themselves. Although it is a shame that this topic should be discussed from a cis-normative angle, perhaps through discussing the dynamics between cis-genders can this paper bring up new topics. Ultimately, this paper hopes to provide a more holistic view of the issue by pointing out possible links between the subjects and to better understand the possible gender bias present in mainstream MOBA games with a broad reach of audience.
\end{abstract}

Keywords: visual culture, digital culture, gaming, multiplayer online battle arena, moba.

\section{INTRODUCTION}

Gaming has come to be considered a top recreational activity in China throughout recent years. Reports show that as of 2021, there are approximately 720 million players in China, with $48 \%$ of those being female [1]. Multiplayer Online Battle Arena (MOBA) is one of the most popular genres coming out of competitive gaming [2]. MOBA games - such as DotA, League of Legends and Smite - focus on strategy and reaction, where a player controls a character and plays with a team of other players to achieve victory, mainly through killing players of the opposite team and taking objectives. MOBA often features 'powerful audiovisual designs, visually appealing characters with hypermasculine and hyperfeminine physical traits, dynamic background music, stunning lighting, and a central theme of group fighting' [3]. 'The game is marked by obvious depictions of violence and expressions of anger, callousness, and aggression, traits closely linked to 'hegemonic masculinity' $[4,5]$, exaggerating the glory of warfare to appeal to the stereotypical male audience.
However, MOBA games are important to analyse due to their large female player base. To take one example, Honor of Kings is a popular Chinese MOBA with $54 \%$ of players being female players. Yet in a 2020 case study by Liu \& Lai of said game, gender bias is a problem which female players face, which manifests itself in ways that hinder the female gaming experience. When interviewed, the players clearly linked their gaming experience to the visual representation of the game characters. This leads to the idea that the way characters are visually presented in games is linked to the gaming experience. The way the characters are visually represented can be detrimental to the experience of female players.

This essay proposes the idea that the visual representation of female playable characters in MOBA games perpetuate harmful stereotypical gender roles, which in turn acts as a mirror in which male players view female players and female players view themselves. This research hopes to explore how female playable characters are visually represented in contrast to male playable characters, focusing on the similarities and differences between them. As argued, the visual 
representation of female characters in games can perpetuate gender roles from games to players. Through the male gaze, the role which the female player takes on in the game can affect both the way that male players view her, but also the way in which she views herself. By reviewing works from Judith Butler, Mary Ann Doane and Laikwan Pang, the game could be thought of as a performance, masquerade or distorting mirror within which gender is expressed. Even though there is abundant research on the female simulacra and female experience in gaming, there are insufficient discussions relating the representation of the female body to the female experience. It is also a shame that this topic should be discussed from a cis-normative angle, but perhaps through discussing the dynamics between cisgenders can this paper bring up new topics. Ultimately, this paper hopes to provide a more holistic view of the issue by pointing out possible links between the subjects and to better understand the possible gender bias present in mainstream MOBA games with a broad reach of audience.

\section{METHOD}

This review paper will focus mainly on textual analysis with some visual analysis in order to illustrate the main point of these texts. Conclusions are drawn through the close reading of other papers, extracting their main findings and ideas in order to relate across the wider discussion of visual media to Chinese MOBA. To supplement the text, the photos of two Chinese MOBA game characters are taken from an official fan website, picked for their popularity as on the website in order to see if the visual representation of these characters fit into the expected model of desirable bodies as seen through the male gaze.

\section{THE TREATMENT OF FEMALE PLAYERS IN MOBA GAMES}

In a 2020 case study conducted by Liu \& Lai on Honor of Kings, among the male players interviewed one implied that there are certain distinctions between characters for female players and characters for male players, saying that female players are more suited to playing characters who are not aggressive and have simple controls [6]. One of the female players who was interviewed stated that men are important players because 'it incurs harm and entails leadership and coordination skills to be front row players', implying misogynistically that female players are not leaders and are not coordinated [6]. Another female interviewee instead disagreed strongly with the idea that female players are worse, viewing it as a social stigma which needs to be overcome [6]. It is unfortunate that the bias towards female players seems to exist not just in MOBA games but in the general gaming sphere.
The same case study also recognised the fact that 'gamers in the King's community habitually use obscene, gender-specific slurs' mostly targeted towards female players [7]. This is also true for the gaming sphere where while insults may be thrown at any player in the game, gender-specific slurs are mostly directed at female players. These remarks bolster the idea that MOBA games foster environments with complicated gender inequality which should be further investigated.

\section{THE VISUAL REPRESENTATION OF FEMALE CHARACTERS VERSUS MALE CHARACTERS}

Liu \& Lai's case study does not leave out the gender bias evident in the visual representation of the game's characters. This bias is also present in games in general, as researchers have found that key playable characters are mostly presented as male whilst female characters are largely under-represented and non-playable, and mostly presented as unimportant, secondary and hypersexualised [8].

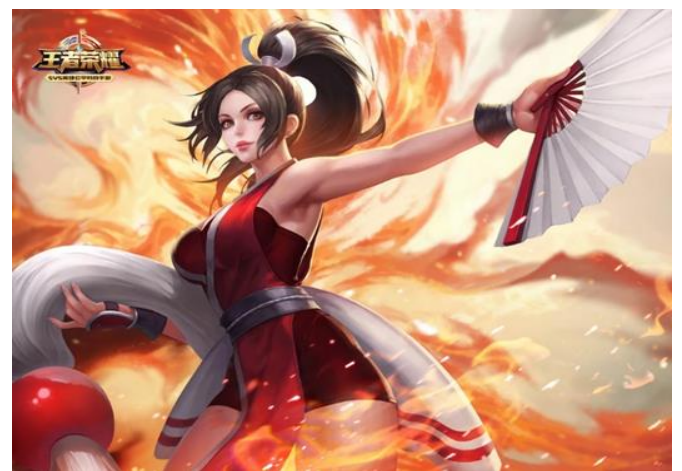

Figure 1. Mai Shiranui, King Glory Wiki [8]

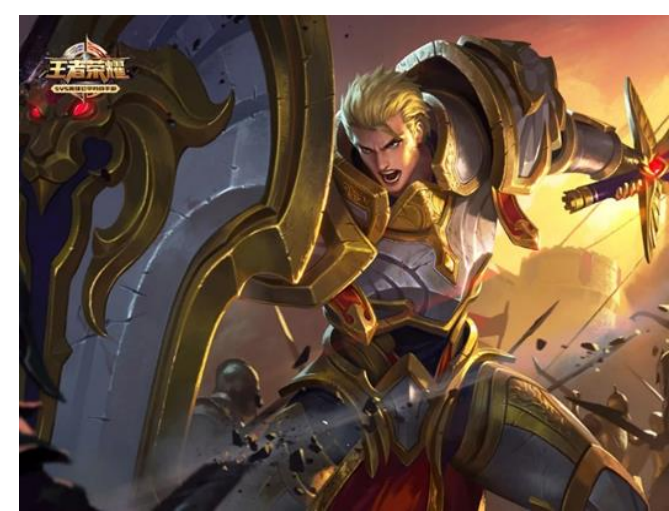

Figure 2. Arthur, King Glory Wiki [9]

Using Honor of Kings as an example, consider the two trending champions on an official fan website King Glory Wiki. Figure 1 shows a female character and Figure 2 shows a male character respectively, both from Honor of Kings. Zooming in to their facial expressions, the female character is smiling while the male character is frowning and yelling in apparent anguish. He is also engaged in battle, holding a sword and a shield mid fight while the female character holds a fan in one hand 
stretching out to the side in no apparent direction. Both of their eyes are looking in the same direction as the object they hold. The gaze of the two characters is both directed away from the vantage point of the viewer, which is from down and up for both, the difference is that the female character is looking to the side in no apparent direction while the male character is looking in the same direction as his shield, inferring that he is looking directly at the enemy he may be fighting. This difference may point to a crucial idea of gendered inattention, where the female object's gaze is unfocused, just as she points the fan in her hand in no apparent direction, while the male character's gaze is focused on another person and the action. The open stance of the female character depicted by her open arms contrasts with the protective stance - hunched over, shield held in front with his sword on the side - of the male character makes her more accessible to the male gaze, therefore sexualising her.

Another difference between the two is setting. Whereas the female character has no objects in the background except for depthless swirls of flame, the male character has a tower and an army in the background. Mai Shiranui is taken out of the concept of fighting, perhaps of action, which is what the game is based on, while Arthur is placed right in the middle of it.

When considering the physical embodiments of the characters, stereotypical gendered attributes are obviously displayed. The female character is depicted with tied up long hair while the male character has short hair. They both do not have facial hair or facial markings. It may be important to note that the female character does not have any body hair, either. Out of the two, only the female character can be visibly seen to be wearing makeup. Expressions of two genders are marked out specifically here with the female character more focused on aspects of her appearance than her male counterpart.

In terms of clothing, the female character is wearing a sleeveless top and shorts while the male character is shown in full body armour. The only protective piece of clothing the female character is wearing are braces on both of her wrists and hands. Finally, both characters do not seem to be wearing any accessories. The stereotype of female characters being scantily clad in games can also be seen in this analysis of one game character. The choice to represent the female character in little clothing is means to satisfy the male gaze, sexualising her in order to make her more accessible as a game character.

The differences lead to the central proposition of this essay. In an analysis of MOBA games, it may be possible to understand why female players are treated as female characters are represented: 'unimportant, secondary and hyper-sexualised' [8].

\section{REFLECTIONS OF GAMING}

\subsection{Gender as constructed and performed, or gaming as a performance.}

Gender and gaming are both performances. Judith Butler stated that gender is constructed and performed [10]. Traits which are considered masculine or feminine are not defined by biology but are discursively constructed and internalised by individuals [11]. The exhibition of gender traits also differs in different social settings [11]. These points are crucial to this paper as it reaffirms the idea that MOBA is created by people, an act in which people take on another persona and inhibit the characteristics of the game character in the game in a performance and something that happens in another setting. The characteristics that the female and male game characters portray are going to be the defining terms of what is feminine and masculine in the game.

\subsection{Gaming as a masquerade.}

Through immersing themselves as the game character in the video game's setting, the video game becomes a form of masquerade for the player. As explained by Mary Ann Doane, a masquerade can create a mode of being for the consumer [12]. As the female player takes on the role of the female character, she is viewed through the male gaze in the setting of a masquerade, and this is the only role she may adopt in this male-dominated sphere. Doane explains that the masquerade devalues femininity [12]. However, the concept of the masquerade can also "provide a feminine counter to the concept of fetishism which had dominated discussion of (male) spectatorship [13].' The concept of femininity does not have to be built upon masculinity - masculinity could simply be the context in which femininity exists [13]. Without femininity, the concept of masculinity would also fail to exist. These two genders are in relation to each other, but they cannot only be seen in opposition to each other as these ideas are transient and their boundaries unclear. If a female playable character displays what are traditionally known as masculine traits, it can be understood that this character is deemed less feminine - less sexual - in the male gaze but no less feminine in essence. However, through the western male gaze, female characters can either be defeminised - to separate the masculine traits from what is culturally acceptable as female - or demasculinised - to undermine the masculine traits which the female character exhibits to keep her as an object of desire - through their visual representation in the masculine gaming sphere.

\subsection{Gaming as a distorting mirror.}

With the idea of self-representation in gaming, the idea of the game can be viewed in the form of a 
distorting mirror. The female player may choose her game character based on his or her visual representation. This research focuses on the visual appearance of game characters and the gender dichotomy between female and male characters, therefore in this specific scenario, female players can project themselves onto the female characters in the game. However, it is important to acknowledge that the female character is being viewed through the male gaze regardless of the player behind her.

Pang makes a note of how John Berger sees the European oil painting traditions functions as a way to make woman treat herself as a sight before anything else, connecting to the mirror image of the woman in a specific environment $[14,15]$. However, as criticized by Pang, 'the autonomous and desiring gaze behind, or symbolized by, the mirror demonstrated by Berger [...] is probably too reductive a model of the modern subject. The modern subject's desire for self-sufficiency cannot be separated from that for self-surrender' $[14,15]$. As the female player puts herself in the social environment of the game, she takes in the female characters' design made to be appreciated in the male gaze and learns, whether consciously or subconsciously, the defining terms of the gendered tension in a game. As the female player takes in her in-game character, the process of internalization happens as the female player projects herself on to the character. 'Berger [...] describe[s] an internalization process of the seeing subject appropriating the powerful eternal gaze to look at oneself, therefore consuming, or fetishizing, one's own images' [14, 15]. Pang also believes that the female viewer is capable of consuming female images as she projects herself on to the desirable image. Pang writes, 'The seen and the seeing are merged, and they mutually implicate each other. This mirror can be compared to Jacques Lacan's extremely influential "mirror stage" theory, in which the mirror reflects the desire of the infantile to hold on to an autonomous and coherent self that experientially is still an impossibility to the infantile' [14, 15, 16]. However, 'Lacan's mirrored selfimage is projected entirely for one's own consumption instead for a hegemonic other - the notion of other is conceptualized as part of the self' $[14,15]$. It is also 'based on the assumption that the looking one is unable to detect the illusory nature of the mirror' $[14,15]$. This is not entirely true in gaming, where players consciously select the characters they want to take on. Nonetheless, it may be that players are oblivious to taking on or being in the male gaze, where the object of vision is warped to become fetishized.

While narratives in games are strongly dominated by male subjects and male characters, the gendered female characters become objects of desire for both women and men. The female players may choose to grasp hold of this opportunity to be represented in the male-dominated sphere, but it must be remembered that the images reflected and produced by the mirroring effect of the RPGs are alienating, although at times pleasurable. Pleasurable for both the male and female consumers but alienating solely for the female consumer. This effect can be seen in the treatment of female players in the study done by Liu \& Lai. Laura L. Sullivan stated in her essay how 'the objectification of women's faces and bodies pervasive in mainstream mass media forms one of the cornerstones of women's oppression. Women internalize this objectification and in turn feel bad about ourselves [...] As Berger explained, "how [a woman] appears to others, and ultimately how she appears to men, is of crucial importance for what is normally thought of as the success of her life. Her own sense of being in herself is supplanted by a sense of being appreciated as herself by another"' [17]. This dichotomy is constantly present as female game characters are being sexualised, undermining the abilities of the character when their worth is focused on how visually appealing she is. Sullivan also elaborated on how the representation of the female body on the internet is sexualised through her research of the keywords 'beautiful women' where there was much nudity. She continues to suggest the possibility that women may not have the intention for their images to be consumed by male viewers [18]. It must be considered that while the female player chooses to be presented in a public sphere dominated by the male gaze, the female character and the female player behind the character may not choose to be seen in the male gaze which sexualises and reduces the worth of female players down to their visual representation.

\section{CONCLUSION}

The visual representation of female playable characters in MOBA games perpetuate harmful stereotypical gender roles, which in turn act as a mirror through which male players view female players and female players view themselves. Through this discussion, the gendering of the gaming sphere and the way female characters are visually represented is detrimental to the experience of female players. This essay hopes to contribute to the existing discussion on the female simulacra and to make a difference in how female bodies are treated, therefore improving the female experience in the gaming sphere.

\section{REFERENCES}

[1] Research and Markets. 2020 Analysis of Gamers in China: Analysis of Gamer Behaviour and Spending by Geography, Gender and Platform. GlobeNewswire News Room, October 22, 2020. https://www.globenewswire.com/newsrelease/2020/10/22/2112716/0/en/2020-Analysisof-Gamers-in-China-Analysis-of-Gamer- 
Behaviour-and-Spending-by-Geography-Genderand-Platform.html.

[2] Gökhan Çakır. What Is a Moba? Dot Esports, June 17, 2021. https://dotesports.com/news/what-is-amoba.

[3] Tingting Liu \& Zishan Lai. From non-player characters to othered participants: Chinese women's gaming experience in the 'free' digital market. Information. Communication \& Society, 2020. DOI: 10.1080/1369118X.2020.1791217. p. 2.

[4] Tingting Liu \& Zishan Lai. From non-player characters to othered participants: Chinese women's gaming experience in the 'free' digital market. Information. Communication \& Society, 2020. DOI: 10.1080/1369118X.2020.1791217. p. 3.

[5] R. Connell \& J. W. Messerchsmift. Hegemonic masculinity: Rethinking the concept. Gender and Society, 2005.

[6] Tingting Liu \& Zishan Lai. From non-player characters to othered participants: Chinese women's gaming experience in the 'free' digital market. Information. Communication \& Society, 2020. DOI: 10.1080/1369118X.2020.1791217. p. 8 .

[7] Tingting Liu \& Zishan Lai. From non-player characters to othered participants: Chinese women's gaming experience in the 'free' digital market. Information. Communication \& Society, 2020. DOI: 10.1080/1369118X.2020.1791217. p. 4.

[8] Fandom. "Mai Shiranui," King Glory Wiki, accessed September 17, 2021, https://kingglory.fandom.com/wiki/Mai_Shiranui?f ile=Mai_Shiranui.jpg.

[9] Fandom. "Arthur," King Glory Wiki, accessed September 17, 2021, https://kingglory.fandom.com/wiki/Arthur?file=Po wer_of_Paladin.jpg.

[10] Butler, J. (1990). Gender trouble: Feminism and the subversion of identity. Routledge.

[11] Bem, S. L. (1974). The measurement of psychological androgyny. Journal of Consulting and Clinical Psychology.

[12] Doane, Mary Ann (1988). Masquerade Reconsidered: Further Thoughts on the Female Spectator. Discourse. 42.
[13] Doane, Mary Ann (1988). Masquerade Reconsidered: Further Thoughts on the Female Spectator. Discourse. 48.

[14] Pang, Laikwan. The Distorting Mirror: Visual Modernity in China. University of Hawai'i Press, 2007. 2-3.

[15] Berger, John. Ways of Seeing. London: BBC and Penguin, 1972.

[16] Lacan, Jacques. The Four Fundamental Concepts of Psycho-Analysis. 1978. Translated by Alan Sheridan. New York: W. W. Nortion, 1981.

[17] Sullivan, Laura L. Cyberbabes: (Self-) Representation of Women and the Virtual Male Gaze. Computers and Composition. Ablex Publishing Corporation, 1997, 192.

[18] Sullivan, Laura L. Cyberbabes: (Self-) Representation of Women and the Virtual Male Gaze. Computers and Composition. Ablex Publishing Corporation, 1997, 194. 